\title{
0 RAP INDÍGENA COMO GUERRA E COMO CULTURA: DESENTENDIMENTOS ENTRE JOVENS E ANTIGOS ACERCA DO ÑANDEREKO
}

\author{
RODRIGO AMARO DE CARVALHO ${ }^{1}$
}

\begin{abstract}
RESUMO
0 presente artigo visa apresentar parte dos dados da minha tese (CARVALHO, 2018) ${ }^{2}$, que teve como tema de pesquisa os grupos de rap indígena da reserva de Dourados/MS. Apresentarei alguns dados relativos a uma série de transformações que constatei, especificamente no que diz respeito às formas como uma parcela de jovens da reserva, que compreende uma categoria nativa Kaiowá importante, qual seja, a categoria ñandereko. Para tanto, elencarei uma série de dados de pesquisa relativos ao meu contato junto aos grupos de rap, mas também das minhas investigações etnográficas nas escolas. Assim, para os jovens, sobretudo aqueles que têm envolvimento com o rap, o ñandereko tem a ver com o cotidiano atual de dificuldades, violências e privações vividas na reserva, aproximando estes significados, tão valorizados no meio do hip hop, com sua cultura.
\end{abstract}

\author{
PALAVRAS-CHAVE \\ Kaiowá; Jovem; Antigo; Ñandereko; Violência.
}

\section{INDIGENOUS RAP AS WAR AND AS CULTURE: DISAGREEMENTS BETWEEN YOUNG AND ANCIENT ABOUT ÑANDEREKO}

\begin{abstract}
This article aims to present part of the data from my thesis (CARVALHO, 2018), which had as its research theme the indigenous rap groups in the reserve of Dourados/MS. I will present some data relating to a series of transformations that I have seen, specifically with regard to the ways in which a portion of young people from the reserve comprises an important native Kaiowá category, namely, the ñandereko category. To this end, I listed a series of research data relating to my contact with rap groups, but also from my ethnographic investigations in schools. Thus, for young people, especially those who are involved with rap, ñandereko has to do with the current daily life of difficulties, violence and deprivation experienced in the reserve, bringing these meanings, so valued in hip hop, closer to its culture.
\end{abstract}

KEYWORDS

Kaiowá; Young; Ancient; Ñandereko; Violence.

\section{LE RAP INDIGÈNE COMO GUERRE ET COMME CULTURE: DÉSACCORDS ENTRE JEUNES ET ANCIENS À PROPOS DE NANDEREKO}

\section{RÉSUMÉ}

Cet article a pour objectif de présenter une partie des données de ma thèse (CARVALHO, 2018), que j'ai comme thème d'investigation dans les groupes de rap indigènes de la réserve de Dourados/MS. Il présentera quelques

\footnotetext{
${ }^{1}$ Professor adjunto do curso de Artes Plásticas da Universidade do Estado de Minas Gerais - UEMG, campus Belo Horizonte.

${ }^{2}$ A pesquisa que resultou na tese só foi possível de ser realizada mediante à bolsa de doutorado concedida pela CAPES.
} 
données relatives à une série de transformations que j'ai pu constater, notamment en ce qui concerne la manière dont une partie des jeunes de la réserve comprend une importante catégorie autochtone Kaiowá, à savoir la catégorie ñandereko. A cet effet, une série de données de recherche liées à mes contacts avec les groupes de rap est répertoriée, mais aussi à mes enquêtes ethnographiques dans les écoles. Ainsi, pour les jeunes, en particulier ceux impliqués dans le rap, il y a un besoin de voir avec le quotidien actuel des difficultés, des violences et des privations vécues dans la réserve, apporter ces significations, si valorisées dans le hip hop, à sa culture.

\section{MoTS CLÉS}

Kaiowá; Jeune; Ancien; Ñandereko; Violence.

\section{EL RAP INDIGENA COMO GUERRA Y COMO CULTURA: DESACUERDOS ENTRE JOVENES Y ANTIGUOS SOBRE ÑANDEREKO}

\section{RESUMEN}

Este artículo tiene como objetivo presentar parte de los datos de mi tesis (CARVALHO, 2018), que tuvo como tema de investigación los grupos de rap indígena en la reserva de Dourados / MS. Presentaré algunos datos relacionados con una serie de transformaciones que he visto, específicamente en lo que respecta a las formas en que una parte de los jóvenes de la reserva comprende una importante categoría nativa Kaiowá, a saber, la categoría ñandereko. Con este fin, enumeré una serie de datos de investigación relacionados con mi contacto con grupos de rap, pero también de mis investigaciones etnográficas en las escuelas. Así, para los jóvenes, sobre todo los que se involucran con el rap, ñandereko tiene que ver con la cotidianidad actual de dificultades, violencia y privaciones vividas en la reserva, acercando estos significados, tan valorados en el hip hop, a su cultura.

\section{PALAVRAS CLAVE}

Kaiowá; Joven; Antiguo; Nandereko; Violencia. 


\section{INTRODUÇÃO}

Ao contrário dos trabalhos de etnologia clássica que, geralmente, iniciam descrevendo o seu primeiro contato com o povo estudado, partindo de início de uma descrição sobre as dificuldades para se chegar a aldeia em que se desenvolverá a pesquisa, meu contato inicial com os integrantes do grupo de rap indígena Bro MCs, tema da minha tese, se deu no âmbito da cidade, que diga-se de passagem, se localiza bastante distante da aldeia que estes habitam. No ano de 2013 conheci os jovens integrantes do grupo Bro MCs na cidade de São Carlos, no interior de São Paulo, em um local bem distante das aldeias do entorno de Dourados - MS, por conta de uma apresentação que estes iriam fazer durante a programação do Encontro Nacional dos Estudantes Indígenas.

A reserva indígena onde eu viria a fazer pesquisa de campo, após esse contato inicial, estão localizadas nas margens do anel rodoviário que circunda a cidade de Dourados, município do Estado do Mato Grosso do Sul. As aldeias Jaguapiru e Bororó, onde a pesquisa de campo se desenvolveu, possuem características bastante urbanas, se assemelhando muito às vilas e favelas do Brasil.

Na Reserva Indígena de Dourados (RID) ${ }^{3}$, que comporta em conjunto as aldeias citadas no parágrafo anterior, o pesquisador se depara com uma situação deveras complexa, qual seja, nesta reserva há presença de indígenas kaiowá, guarani e terena. Assim, como se não bastasse as inúmeras disputas por conta da carência de espaço, os conflitos são ainda mais corriqueiros em função dos contatos interétnicos que colocam frente a frente distintas cosmologias e organizações sociais.

Durante toda minha pesquisa, levando em conta várias estratégias, tentei arranjar um lugar para residir na Reserva Indígena de Dourados, mas, em todas as tentativas, meus esforços foram frustrados. Por conta disso, decidi me mudar para Dourados para ter um contato mais intenso e contínuo com os Kaiowá. Com isso, levei parte da minha mudança em meu carro particular, alugando uma casa na cidade. Assim, minha pesquisa passou a ocorrer também fora da reserva, dado que, constantemente, também os recebia em minha casa, juntamente com suas respectivas esposas, filhos e filhas. Sendo assim, minha pesquisa de campo se deu em três distintas fases: 1- uma viagem para São Carlos-SP, quando conheci o grupo, e três viagens de 20 dias para Dourados; 2 - posteriormente, mantive residência fixa e permaneci na cidade de Dourados durante o período de 14 meses; 3- e, por fim, fiz duas curtas viagens a campo, com a intenção de fazer mais algumas entrevistas e registrar mais imagens da reserva, totalizando 18 meses de pesquisa de campo.

\footnotetext{
${ }^{3}$ A RID foi "criada pelo Serviço de Proteção ao Índio - SPI, em 1917, pelo Decreto Estadual 401 de 1917, com 3.600 ha. Esta área foi, inicialmente, reservada aos índios da etnia kaiowá, que já ocupavam o local e suas imediações (PEREIRA, 2014, p. 2).
} 
Os próprios indígenas e os pesquisadores mais experientes da região me desencorajavam a tentar permanecer na aldeia, relatando os perigos iminentes da minha estadia por lá. Todavia, com o passar do tempo, pude constatar a veracidade deste fato, mas entendi que estas negativas também tinham a ver com aspectos relacionados à organização social Kaiowá. A corresidência é um fator importantíssimo para estes indígenas, pois acreditam que residir em um mesmo espaço e compartilhar do mesmo alimento implica tornar-se parente (PEREIRA, 2004). Ademais, creio que, para além das questões que tangem à dimensão da produção de proximidade e da manutenção de distanciamentos, temos que levar em conta também a própria proximidade existente entre aldeia e cidade, dado que a cidade é tida como o lugar do karaí. ${ }^{4}$

Nas aldeias Jaguapiru e Bororó, minha vivência buscou acompanhar o cotidiano familiar dos jovens que integram os grupos Bro MCs e Jovens Conscientes, bem como outros espaços e momentos de suas vidas, tais como os momentos escolares, as rodas de tereré, pescarias e os momentos de diversão nos campos de futebol. Destes momentos de convivialidade, destaco as rodas de tereré como um momento importante para entender muito da dinâmica dos grupos e das representações que são valorizadas por estes jovens. Além desses espaços, acompanhei também a gravação de um videoclipe e pude etnografar algumas apresentações do primeiro grupo citado.

Por conta da impossibilidade de estar em campo tal como nos moldes dos trabalhos de campo mais clássicos e, principalmente, pelo fato de os jovens cantores de rap trabalharem de segunda a sexta, como em nosso padrão de horário comercial, eu, praticamente, não conseguia estar com eles durante a semana. Com exceção de Bruno, que trabalha como monitor do Projeto Mais Educação, na Escola Municipal Indígena Ará Porã, todos os demais, tanto do grupo Bro MCs quanto do Jovens Conscientes, como disse acima, se revezam entre trabalhos sazonais nas fazendas do entorno da aldeia e na construção civil, como serventes de pedreiro na cidade de Dourados. Tendo em vista esta limitação, caso eu quisesse manter contato com os jovens interlocutores de minha pesquisa, eu me via obrigado a circular pela aldeia justamente nos dias em que estava mais suscetível a me deparar com casos de violência, dado que são nos fins de semana que se pode perceber o aumento do consumo de bebidas alcoólicas e, consequentemente, aumento nos índices de violência. Devido a isso, comecei a fazer pesquisa de campo em duas escolas indígenas da aldeia - Escola Municipal Indígena Agustinho e Escola Estadual Guateka Marçal de Souza.

Em paralelo ao tempo que consegui passar nas escolas, procurei manter relação direta com os integrantes dos dois grupos. A maior parte do tempo, interagíamos no quintal de suas casas, tomando bastante tereré, ouvindo e conversando sobre rap, mas também

\footnotetext{
${ }^{4}$ Traduzindo do guarani para o português, o karaí para os Kaiowá se refere ao não-indígena branco.
} 
sobre assuntos específicos do cotidiano da reserva, sobre os cuidados com suas crianças, sobre suas relações familiares, sobre a cidade de Dourados, entre outros. Рara além do espaço da reserva, com o grupo Bro MCs, viajei para algumas localidades no estado do Mato Grosso do Sul.

No que diz respeito ao aprendizado da língua nativa e à minha comunicação em campo, durante todo tempo de pesquisa, me esforcei muito para aprender o máximo possível e para pôr em prática o que aprendia. Em uma determinada ocasião, em um evento na Escola Tengatuí Marangatu, conheci uma importante pessoa para minha pesquisa, refirome aqui ao Professor Rogério Vilharva, da etnia Kaiowá. Rogério foi um dos mais importantes interlocutores e colaboradores da minha pesquisa. Durante vários meses, nas manhãs de domingo, deslocava-me de minha residência até sua casa na aldeia Bororó. Nessas ocasiões, o Professor Rogério se dispunha a me dar aulas de guarani e também me auxiliava na transcrição e na tradução das letras e falas dos jovens cantores de rap, gravadas por mim em suas apresentações. Além desses momentos voltados para o aprendizado da língua, enquanto nos refrescávamos com o tereré, conversávamos muito sobre o cotidiano da reserva.

\section{JUVENTUDE, VIOLÊNCIA E O RAP KAIOWÁ E GUARANI DAS ALDEIAS JAGUAPIRÚ E BORORÓ, DOURADOS-MS}

No Estado do Mato Grosso do Sul, com a chegada e a ocupação do espaço por parte dos não-índios, os ameríndios, em pouco mais de cem anos, se viram diante da inexorável transformação de seus territórios por conta das fazendas e das cidades. Em termos numéricos, para se ter uma ideia geral, a RID em seus míseros 3475 hectares abriga uma população de aproximadamente vinte mil pessoas. Além das três etnias anteriormente citadas, a RID ainda agrega indígenas de outras origens étnicas, como Bororo e Kadiweu, além de alguns poucos regionais (brasileiros e paraguaios), normalmente agregados a parentelas indígenas, por terem contraído casamentos com membros de alguma das etnias que vivem na RID (PEREIRA, 2014, p. 15). É importante destacar também que a proximidade da cidade colocam os indígenas da reserva com vários problemas próprios do mundo dos brancos, como poderíamos citar, por exemplo, o excessivo consumo de álcool e demais drogas consideradas ilícitas, tanto por parte dos adultos quanto por parte dos jovens ${ }^{5}$.

Conforme Antonio Brand (1997), para compreender os alarmantes índices de violência observados entre os jovens kaiowá, nos últimos anos, se faz necessário voltarmos

\footnotetext{
${ }^{5}$ Assim, a falta de espaços na aldeia, a complexidade dos contatos entre as diferentes etnias, somadas à estas práticas de consumo adquiridas a partir do contato com o mundo dos brancos, adiciona mais um ingrediente extremamente nocivo para os dilemas complexos enfrentados pelos indígenas da reserva.
} 
para a sua história, marcada por um dos processos mais radicais de confinamento geográfico e cultural.
"a demarcação das assim denominadas reservas indígenas, pelo Serviço de Proteção aos Índios, SPI, entre os anos de 1915 e 1928, constituiu-se em importante estratégia de liberação dos territórios indígenas para a colonização, ao total arrepio da legislação em vigor" (BRAND, 1997, p. 40).

Os indígenas das etnias Kaiowá e Ñandeva, que ocupavam tradicionalmente a região conhecida geograficamente como o Cone Sul do antigo Estado do Mato Grosso, agora dividido em duas partes, foram compulsoriamente obrigados a ocupar diminutas reservas indígenas. Assim, as violências atuais que atingem os indígenas destas aldeias são decorrentes desse confinamento histórico, tornado possível pela histórica conivência e submissão da política indigenista dos diversos Governos aos interesses maiores da economia regional.

Esse quadro de confinamento, em áreas extremamente diminutas obrigou os indígenas a venderem sua mão de obra em serviços braçais, nas fazendas e nas cidades do entorno. Pensar o destino dos índios, enquanto futuros trabalhadores nacionais, expressa o lugar a eles reservado na estrutura de classes da sociedade brasileira do início do século XX, na medida que estes necessariamente "deveriam abandonar suas práticas culturais para assumir a condição de trabalhadores nacionais, no interior da cultura nacional, considerada mais evoluída" (PEREIRA, 2014, p. 46).

O confinamento nas aldeias também é responsável direto pela violência interna nas aldeias. Neste sentido, grande parte dos assassinatos são praticados pelos próprios indígenas. Todavia, esta realidade não exime os não-índios, levando em conta que estes tiveram participação efetiva neste processo de desagregamento interno. Como observa Levi Pereira (2014), os homicídios estão relacionados, na maioria das vezes, às dificuldades de se resolver os conflitos internos entre os grupos familiares, decorrentes da interferência estatal ao longo do século XX, que produziu o confinamento dos Kaiowá nas reservas, além de criar a figura dos capitães. ${ }^{6}$ Estes, muitas das vezes (nem sempre) eram líderes familiares legítimos, mas eram alçados a uma posição de opressão sobre as demais famílias vivendo em um dado espaço.

Segundo Antonio Brand, os jovens podem ser considerados como uma das maiores vítimas da violência causada pelo confinamento?

\footnotetext{
${ }^{6}$ Os capitães são lideranças locais eleitas pela população das aldeias. Para saber mais sobre o processo de eleição e acerca do papel exercido por estes, ver Pereira (2014).

7 "Essa violência é, inclusive, uma das causas para os deslocamentos de muitas famílias para a beira de estradas e/ou periferias urbanas, percebidas pelos índios como únicos espaços nos quais ainda é possível, embora em condições precárias, deslocar-se, ou desenvolver a prática do oguata (caminhar), em casos de conflitos e/ou tensões de diversas ordens" (BRAND, 1997, p. 43).
} 


\begin{abstract}
"São os jovens que se percebem, hoje, sem lugar dentro das pequenas extensões de terra, superpovoadas, que os Kaiowá e Guarani conseguiram manter até o momento frente à sanha insaciável do agronegócio e, sem lugar fora das terras indígenas, nas pequenas e médias cidades localizadas no entorno, nas quais esses mesmos jovens se percebem, cotidianamente, como personas non gratas e não bem vindas e bem vistas" (BRAND, 1997, p. 43).
\end{abstract}

Por conta deste quadro complexo é que, sobretudo dentre os jovens, ocorrem muitas mortes por enforcamento, em sua maioria, associadas a acusações de assassinato, seja por feitiçaria, ou por meios "mais diretos", como envenenamento, como bem observou Spensy Pimentel. Sendo assim, percebemos que há um quadro de desagregação e conflito onipresente, e que são sintomáticos do mal-estar imperante nas reservas: como conviver com pessoas de quem se desconfia constantemente? As suspeitas de feitiçaria ou de assassinato, por sua vez, geram novas violências e vive-se, atualmente, um círculo vicioso nesses espaços (PIMENTEL, 2006).

Os dados apontados pela bibliografia podem ser observados nas letras de ambos os coletivos de rap ameríndio, bem como nos relatos por mim colhidos nas falas dos jovens kaiowás e guaranis na Assembléia de Jovens e Crianças, que ocorreu na aldeia Tey'i Kue. Assim, Sidney e Jânio, kaiowás que compõem o grupo Jovens Conscientes, acerca destas questões, cantam e rimam assim: "Eu sou da raça do indiozinho sem escola, pra você pedindo esmola. Triste, oh foi tirado, humilhado nas ruas, e na aldeia hoje vaga muito louco buscando algo melhor nessa vida". Além disso, o uso de drogas também é tema bastante frequente na letra do grupo em questão, vejamos: "Mita'i pyahu ropita umi petÿ vai" (Criança desde muito cedo já começa a fumar maconha; Tradução nossa). (...) "Eu estou chegando pra cantar essa música, mostrando a realidade do dia a dia que é dramática, jovens fuma 'um' e deixa a vida problemática" (Não julgue pelas aparências - Jovens Conscientes).

Em linhas gerais, tanto nas entrevistas como nos conteúdos de suas rimas, fica patente a aproximação por parte dos jovens rappers da reserva de Dourados com um contexto histórico, de certo modo, comum à realidade de todas periferias brasileiras. Sobre esta taxativa, poderíamos citar um trecho de uma entrevista de um dos integrantes do grupo de rap Brô MC's: "Aldeia é como favela. O que muda é que lá eles usam fuzil e aqui é facão", compara Kelvin, que são as temáticas recorrentes nas letras de Rap dos grupos mais conhecidos no Brasil, como por exemplo, Racionais MC's, Facção Central, Sendo assim, temas como a desigualdade social, a violência (urbana) e o racismo, são assuntos importantes tratados pelos jovens indígenas em suas rimas, que aproximam estes temas próprios de outros contextos com as violências internas das aldeias, com a fome e com o racismo sofrido por estes na cidade de Dourados. 


\section{ENTRE A TRADIÇÃO E A PERIFERIA: "ANTIGOS", "JOVENS" INDÍGENAS E 0 MUNDO DOS BRANCOS}

É no contexto descrito anteriormente que muitos "jovens" indígenas das aldeias de Dourados entraram em contato com o universo hip hop. Neste ínterim, muitos produtos advindos do mundo dos brancos passam a ser desejados pela juventude indígena, tais como bonés, camisetas, tênis, moletons e variados produtos eletrônicos. Neste contexto, é importante lembrar que a escola assume uma importância considerável nesse processo. É na escola, muitas das vezes, que os jovens entram em contato com estilos e poderes aquisitivos distintos da reserva. A escola é o espaço da homogeneização, com seus métodos de padronização e de disciplinar os corpos, mas também é o espaço do encontro da diferença, expressa tanto nos comportamentos e gostos, mas, sobretudo, no consumo.

A necessidade de se estabelecer um debate acerca dessa parcialidade da população estudada se deu por conta da constante discussão interna do que atualmente vem sendo chamado de "jovens", em contraposição a "antigos". Neste sentido, os adventos implementados pelos componentes dos grupos de rap indígena da reserva colocam em pauta mais uma vez essa discussão, atualizando, sobretudo, as discussões internas no que diz respeito à abertura ao mundo dos brancos e suas consequentes transformações.

Como bem salientou Célia Silvestre (2011), que fez pesquisas sobre os jovens acadêmicos Guarani e Kaiowá do cone Sul do Estado do Mato Grosso do Sul, apesar de a categoria jovem ser nova nesse universo social, esta forma contemporânea de classificação etária é atualmente muito utilizada. Tendo em vista que, conforme a cultura dita tradicional, os Kaiowá "não se organizam segundo faixas etárias com recortes cronológicos rígidos diferentemente de outros coletivos, por exemplo, os Xavante (MAYBURY LEWIS, 1984) - eles subdividem as fases da vida de acordo com ciclos biológicos e produtivos". Para estes coletivos, a puberdade é tradicionalmente vista como marco de passagem entre ser criança (mitã ou mitã $\imath_{i}$ criança ou criança pequena, respectivamente) e se tornar adulto (kuimba'e ou kunhã; homem e mulher, respectivamente), uma vez que não há as categorias intermediárias de adolescente e jovem. Todavia, para que esse processo se complete, para que a pessoa Guarani se consolide, há que passar por dois ritos: o menino, pelo Kunumy Pepy (ritual de furação do lábio inferior), e a menina, pela Menarca (rito que envolve uma série de cuidados e prescrições na chegada da primeira menstruação). E, posteriormente, se casar e ter filhos e, por fim, seus filhos terem seus respectivos filhos para que assim a geração esteja completa, concretizando um novo fogo nuclear ${ }^{8}$.

\footnotetext{
${ }^{8}$ Os critérios para definir o que é ser jovem na reserva de Dourados são relativamente díspares e distintos. Por vezes, os jovens eram englobados junto das crianças, em outras ocasiões, eram identificados com a vida estudantil, ora eram definidos pela idade de casamento.
} 
A importância do parentesco expressa na necessidade de viver e constituir parentela foi observada por mim no momento em que Kelvin rompeu seu casamento com sua primeira esposa e passou a residir sozinho. A condição de solteiro, somada à possibilidade de viajar para fazer shows e, vez ou outra, conseguir algum dinheiro advindo dos cachês das apresentações, colocava o jovem em uma situação ímpar diante dos outros jovens da reserva e também em comparação aos demais integrantes do grupo.

Nestes tempos, então, podia-se observar quão deslocado ficava diante de seus familiares e dos demais amigos casados. Foi neste tempo que menos vezes encontrei Kelvin na aldeia. Sempre que ia jogar futebol com os demais rapazes na Vila Olímpica, ele, que antes ега um dos primeiros a chegar, estava ausente. Os outros garotos diziam que ele "tá com os outros parceiros".

A este respeito, Levi Pereira aponta que, após o rompimento do laço conjugal, "independentemente da posição ocupada pela pessoa na vida social da comunidade, ela volta a ocupar a única posição social estrutural reservada ao solteiro, que é a de mitã guasu (rapaz ou moça solteira), pessoa considerada volúvel e instável, sem muito compromisso com a ordem pública". E continua, acrescentado que "o descrédito do adulto sem cônjuge impeleo ou constrange-o a num tempo breve reconstituir novamente um fogo e voltar a desempenhar as atividades atribuídas a um adulto pertencente a um fogo" (PEREIRA, 2004, p. 59-60). Neste caso, se ele não se casar em um determinado tempo, verá sua imagem ruir diante da sua parentela e da aldeia. ${ }^{9}$ E, de fato, o período de solteirice de Kelvin foi um momento de tensões e distanciamentos entre os integrantes do grupo.

Tendo em vista o exemplo de Kelvin, entre estes coletivos étnicos a categoria jovem pode ser aplicada tanto a uma pessoa que nós entendemos como adolescente, tendo por volta de 14 anos, quanto a uma pessoa de 30 anos que ainda não tenha se casado ou que seja separada e não tenha filhos. Além disso, Tonico Benites (2009) destaca também que o consumo de certos produtos também coloca ainda mais indefinição nessas questões. Assim, ser jovem entre os Kaiowá, atualmente, também se refere a determinadas práticas e gostos (PIMENTEL, 2007; BENITES, 2009, 2013), como, por exemplo, ser acadêmico ou se envolver com o hip hop.

Os questionamentos citados anteriormente por parte dos xamãs da região acerca da repercussão nacional do trabalho proposto pelo Bro MCs são mais uma forma de representar a oposição existente entre "antigos" e "jovens" na reserva. Conforme salientou Levi Pereira (2004b, p. 271), é importante ter em vista que a categoria "antigo" não diz

\footnotetext{
${ }^{9}$ Atualmente, o casamento é tido como uma alternativa possível para controlar o comportamento desviante dos jovens da reserva. Assim, muitas uniões são precocemente incentivadas pelas famílias envolvidas. No entanto, as famílias se encontram em uma situação ambígua, pois atribuem à vida escolar a saída para a condição difícil da reserva, mas o caminho dos estudos acaba por postergar o ato do casamento.
} 
respeito a "apenas uma categoria de idade, expressa também a ideia de uma pessoa com bastante experiência, sabedoria e expressão social, com grande conhecimento sobre o 'sistema e modo de ser Kaiowá' "(PEREIRA, 2004b, p. 271) Nesse sentido, Pereira acrescenta que "é possível que uma pessoa com menos de 40 anos possa considerar-se e ser considerada velha, desde que possua netos e tenha sob sua influência um grupo de parentes" (PEREIRA, 2004b, p. 271).

Essas novas práticas fizeram surgir um novo tipo de protagonismo, expresso pela expressão "liderança jovem". Uma das explicações para o surgimento deste protagonismo juvenil está relacionado às transformações provocadas pelo mercado de trabalho e pela escolarização crescente da reserva indígena de Dourados. Assim, professores indígenas, diretores e coordenadores pedagógicos, profissionais da saúde indígena e pessoas envolvidas em projetos de resgate e valorização cultural têm exercido um papel importante de liderança cada vez mais necessária na mediação e na captação de recursos advindos do mundo dos brancos.

E no caso mais específico dos meus interlocutores de pesquisa, essa figura de liderança é exercida por Bruno Veron, que, além de conduzir o coletivo de rap Bro MCs, fazendo uma ponte com o produtor que mora na cidade e repassando as informações para os demais integrantes, é tido pelos mais novos que gravitam em torno do grupo como uma figura de destaque. Esse protagonismo de Bruno não se dá somente nessa ponte com o mundo dos karai, mas pode ser percebido também de diversas outras formas, como, por exemplo, no próprio palco, na composição de muitas letras e na concessão de entrevistas. Este protagonismo só é diluído pela figura de Kelvin Peixoto que, igualmente, por vezes, se destaca também nos palcos e nas entrevistas.

\section{IMAGEM 1 - AOS COMANDOS DO LÍDER BRUNO, OS JOVENS ENSAIAM UMA COREOGRAFIA DE STREET DANCE.}

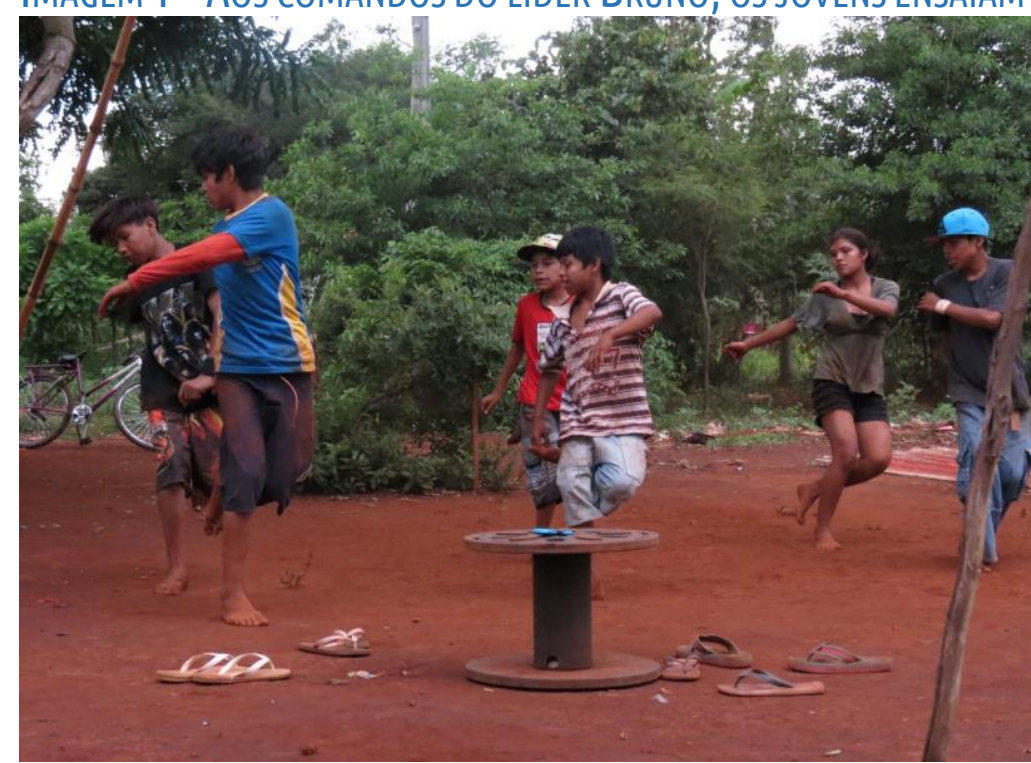

Créditos: Rodrigo Amaro. 
Por dominarem boa parte dos códigos e habilidades advindos do mundo ocidental, os jovens exercem papel importante de mediação entre a cidade de Dourados, a capital do Estado e Brasília. Nessa parcela geracional, incluo também aqueles que já são casados e têm filhos, não sendo considerados tradicionalmente jovens, mas que, por serem escolarizados e saberem lidar com a tecnologia, são enquadrados em oposição aos "antigos", como destacamos anteriormente. Portanto, atualmente se considera jovem em oposição a antigo não só aquele e aquela que já têm passado pela puberdade e não tenham filhos, mas a juventude, para os Kaiowá, também se relaciona a um domínio de uma gama de práticas e saberes. Assim, é importante destacar aqui que, neste caso, a categoria jovem se opõe ora à categoria adulto, ora à categoria antigo, por vezes, se polarizando também em relação a ambas.

Em contrapartida, os "antigos" são aqueles que, mesmo com todo ambiente de contato, ainda detêm e praticam os saberes ditos tradicionais da cultura. Estes, apesar de reconhecerem alguns ganhos e necessidades provenientes do mundo dos brancos, e conscientes da inexorabilidade das transformações do processo de contato, defendem os saberes cosmológicos como explicação e saída para o quadro atual pelo qual estes coletivos vêm passando.

A consciência e a importância das transformações para os coletivos Guarani são salientadas pelos estudos históricos estabelecidos por John Monteiro.

\begin{abstract}
"Radicada não apenas na evocação da mitologia heroica como também no conhecimento esotérico dos cantos sagrados, a ação dos karaí era, a um só tempo, tradicional e transformadora. Tradicional, pois buscava preservar dois elementos fundamentais para os Guarani: sua identidade e sua liberdade (SCHADEN, 1974: 105; MELIÁ, 1988: 93-120); e transformadora porque pregava a destruição da ordem existente justamente com vistas a alcançar o primeiro objetivo (...) Tradição e mudança: a articulação entre estes dois elementos é, para alguns autores, não apenas uma permanente fonte de conflito, como também o próprio motor da história guarani" (MONTEIRO, 1992, p. 482) ${ }^{10}$.
\end{abstract}

Portanto, embora existam conflitos geracionais entre antigos e jovens, sabemos, desde os clássicos, que, a bem da verdade, transformação e mudança não configuram um problema sequer para os mais velhos, pois até o que é dito tradicional foi produzido (e se produz) pelas desejosas relações com outros mundos.

\title{
TRANSFORMAÇÕES DO PRINCÍPIO ÑANDEREKO. OU COMO OS JOVENS ENTENDEM A CULTURA E A "CULTURA"
}

\footnotetext{
${ }^{10}$ Para os coletivos Ñandeva de determinadas localidades, ao contrário dos Kaiowá, Karaí não diz respeito à figura do branco, mas às lideranças espirituais. Eles designam o branco, assim como os Mby'a, pela expressão Juruá.
} 
A partir daqui daremos continuidade à discussão postulada no tópico anterior, passando agora para a abordagem de uma categoria importante para os coletivos Guarani, qual seja, a expressão ñandereko. Assim, uma dimensão essencial do mundo Guarani é expressa pelo prefixo eko, que, conforme Montoya, diz respeito ao modo de vida guarani: ao "ser, estado de vida, condición, estar, costumbre, ley, hábito" (MONTOYA, 1876). Esta tradução é muito próxima das explicações dadas a mim pelos meus interlocutores em campo: "jeito, costume, modo de ser, maneira de viver, sistema" ${ }^{11}$.

O prefixo eko dá origem então ao ñandereko, sendo ñande, pronome da $1^{a}$ pessoa do plural, "nós", inclusivo, nessa perspectiva, da forma como descrito, deixa entrever uma clara oposição entre um tipo de eko e um eko dos "Outros"12. Portanto, temos que ter em vista que não há uma definição substantivada de um "modo de ser" próprio aos Kaiowá e Guarani, e isto se explica por dois motivos: 1- porque o ñandereko varia entre os núcleos familiares destes coletivos; 2 - se explica também pelo fato de que, como vimos, segundo a etnografia de Evaldo Silva (2010, p. 227) sobre os Mbýa e Ñandeva setentrionais, o modo de ser pode variar ao longo da vida, de acordo com os encontros e alterações ao longo das suas trajetórias.

Nesse mote, nos deparamos com a problemática que diz respeito aos maus entendidos interétnicos existentes nas traduções feitas pelos antropólogos da categoria nativa ñandereko, mormente traduzido como cultura. Essa noção, a meu ver, foi pouco problematizada, sendo traduzida de forma automatizada dentro de nossos próprios termos, sem muitos cuidados. Tendo como referência a pesquisa de campo e inspirado pela discussão de uma série de etnografias sobre esta temática, intento contribuir para a discussão aqui da problemática da polissemia do termo ñandereko, na perspectiva dos jovens. O termo é utilizado pelos Kaiowá em diferentes instâncias e espaços, com sentidos diversos, variando bastante conforme o contexto e a faixa etária daqueles que o utilizam. Assim, "jovens" e "adultos" atribuem sentidos distintos a essa importante noção.

Sobre esta problemática, as contribuições de Deise Lucy Montardo (2002), que fez pesquisas sobre a música de distintos coletivos Guarani nas regiões de Amambai e Pirajui, são valorosas por chamar a atenção sobre um problema específico bastante presente na produção etnológica dos "guaraniólogos", qual seja, as dificuldades que remetem aos problemas de tradução. Neste sentido, Montardo destaca que se me baseio na tradução nativa, "estou trabalhando com a tradução da tradução, e para destrinchá-la, teria que reler

\footnotetext{
${ }^{11}$ Essas traduções, inclusive, se aproximam bastante também da tradução feita por Tonico Benites (2013) no glossário estabelecido pelo acadêmico indígena no final de sua dissertação.

${ }^{12}$ É importante lembrar também que o prefixo eko (ou ecó/icó) pode também ser traduzido por estar, o que acaba dando mais força para o argumento que estamos apresentando aqui, que caminha ao encontro da dessubstancialização e da transitoriedade desta noção (LEMOS BARBOSA, 1951 , p. 53 e 68).
} 
com critério as fontes históricas e pensar em todo o processo de construção da tradução" (MONTARDO, 2002, p. 29).

Ainda temos outro ponto importantíssimo para se ter em vista, me refiro à substantivação promovida pela escolarização e pelo mundo acadêmico, que lança mão de uma série de dicionários guarani para definir tais vocábulos (GALLOIS, 2014). Esses usos escolares e acadêmicos criam um núcleo duro para o que seria o ñandereko, que, muitas das vezes, acaba virando sinônimo de "cultura" e de todos os sentidos comuns que nós atribuímos às culturas indígenas, tais como o naturalismo, sustentabilidade, tradição em oposição à modernidade, exotismo, entre outros.

Partindo destes dois problemas colocados sobre os usos e sentidos da noção ñande reko na contemporaneidade e, principalmente, levando em conta tudo que já foi abordado até aqui, gostaria de tratar sobre os significados atribuídos atualmente a esta expressão na perspectiva dos jovens Kaiowá, sobretudo aqueles que estão envolvidos com o hip hop. Resgatando o histórico de envolvimento destes jovens com os projetos culturais realizados na escola e também com seus respectivos parentes que cursam as licenciaturas indígenas oferecidas na região de Dourados, é que podemos entender como esta importante categoria do pensamento Guarani é transposta para o que eles entendem hoje por ñandereko. Em outras palavras, se a escola os incentiva na prática da objetivação pela via do discurso da "valorização da cultura", o rap forneceu outros elementos que vêm promovendo uma transformação nos modos tradicionais de se pensar o ñandereko. Sendo assim, nos resta a seguinte questão: se o ñandereko é traduzido corriqueiramente como a "nossa vida", qual seria então a vida que o jovem leva nas aldeias Jaguapiru e Bororó? E como o jovem, então, entende essa tradução corrente de ñandereko dentro dos seus modos de vida atuais na reserva indígena de Dourados? Vamos deixar as possíveis respostas para essas questões para mais adiante.

\section{A PESQUISA DE CAMPO NA ESCOLA MUNICIPAL INDÍGENA AGOSTINHO - ALDEIA BORORÓ}

Em campo, na Escola Agostinho, trabalhei algumas oficinas com os alunos das turmas de sexta série até as do nono ano. A pedido do Coordenador pedagógico César Benites, indígena Kaiowá, ministrei oficinas que versavam sobre a história do Hip Hop. E como consegui chegar até a esta escola indígena? E, por que, estas temáticas foram abordadas nas oficinas? Durante os dias de semana, sem ter muito o que fazer em campo, por causa da dinâmica de trabalho dos jovens do Bro MCs, participava de eventos variados na reserva. Assim, em determinada oportunidade, acompanhei a Feira dos povos indígenas no NAM (Núcleo de Assuntos Múltiplos) da aldeia Jaguapiru. Neste evento tive a oportunidade de conhecedor o coordenador pedagógico da Escola Agostinho, César Benites. 
César, ao me contar sobre o cotidiano da escola, me disse que não conseguia entender muito bem o comportamento dos alunos, me convidando para ir à Escola para observar os desenhos que os alunos faziam, bem como suas roupas, para que eu pudesse explicar a ele também um pouco da história do hip hop. Em suma, de acordo com César, os alunos da escola que se vestiam com roupas de hip hop e que escutavam rap durante o recreio eram os mais problemáticos. Por isso, ele gostaria que eu trabalhasse com os alunos sobre o histórico do movimento hip hop.

Tendo como referência as observações que fiz no entorno deste espaço, observando a dinâmica dos alunos, percebi ali que havia um movimento diferente e uma certa organização da ocupação de determinados espaços do entorno escolar. A estrada que passa bem em frente à Escola tem um grande fluxo de pessoas pois dá acesso à cidade e faz a ligação com outras regiões importantes da reserva, além do próprio ir e vir dos alunos e demais funcionários da escola. Neste ínterim, percebi a formação de pequenos aglomerados de alunos que se concentravam em pontos distintos nos arredores da escola, indicando pistas sobre a formação de grupos.

Estes grupos de jovens utilizam as vestes do hip hop de forma interessante. Valendose de certa ambiguidade possibilitada por elas, pois ao mesmo tempo em que moletons com capuz, bonés e lenços que cobrem o rosto produzem diferença tanto dentro quanto fora da reserva, eles permitem a (in)visibilidade dos jovens, por esconderem seus rostos nos momentos de perigo e, no limite, na efetivação da iminente violência que ronda as aldeias. Esta observação mais uma vez nos possibilita uma comparação dos jovens dos grupos de rap com os jovens das escolas que consomem o rap, visto que este dado nos permite abordar estes distintos modos de usar as roupas do hip hop: para os jovens dos grupos de rap, estas vestes são utilizadas, principalmente, com vistas a criar uma alteridade diante dos setores dominantes da cidade de Dourados e também para produzir diferença dentro da própria aldeia; já para os jovens "malucos", além de servir como modo de produzir alteridade e relações entre os pares, mormente, estas roupas são utilizadas com o objetivo de produzir invisibilidade nos momentos em que a função jaguar é acionada por eles. 
Imagem 2 e 3 - Jovens indígenas, moradores da aldeia Bororó em entrevista para Associação dos Jovens Indígenas (AJI).
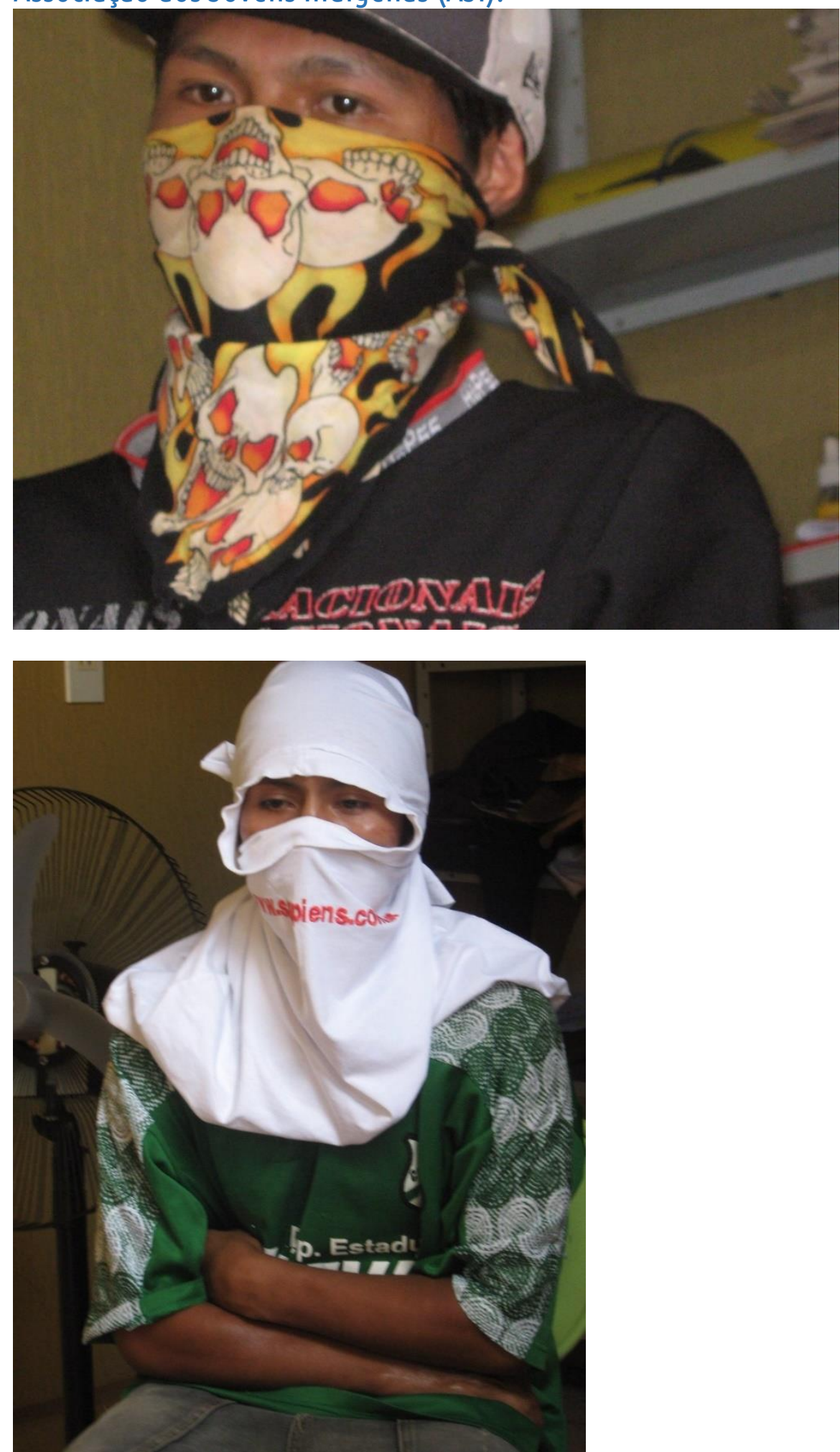

Créditos: Associação dos Jovens Indígenas (AJI).

Esta experiência específica da minha pesquisa de campo nos permite estabelecer um paralelo entre os dados obtidos pelas interpretações dos jovens alunos da Escola Agostinho sobre o que seria para eles o rap e o hip hop, fechando uma linha de interpretação 
que conecta os dois lados dessa experiência de pesquisa. Após as oficinas, feitas de modo interativo através de muitos recursos audiovisuais, esperava que os jovens me dessem respostas bastante óbvias. Todavia, o resultado dos trabalhos escritos e dos desenhos me revelou dados interessantes, que, apesar de serem bastante consensuais entre os alunos, a meu ver, não perdem de forma alguma em significância. Na imagem a seguir, destaco uma das muitas representações do que os alunos entendiam sobre o que eram o rap e o hip hop.

Imagem 4 - Grupo de jovens indígenas armados com facões, lanças, foices e machetes, portando vestimentas próprias do hip hop.

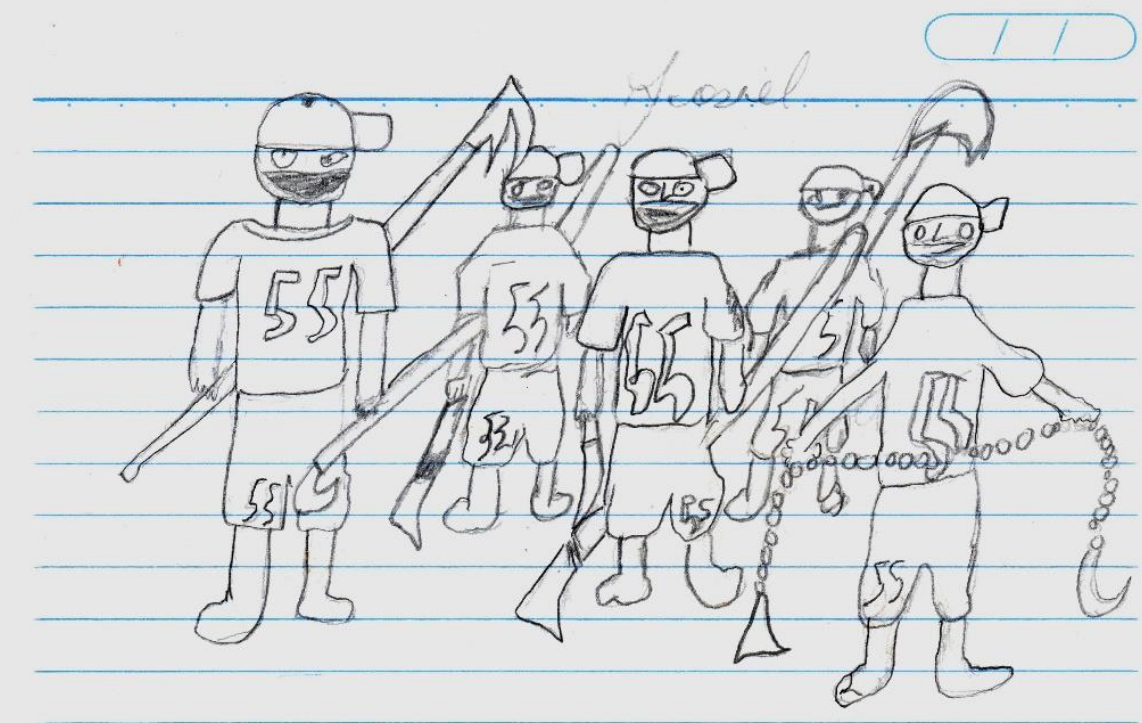

\section{Créditos: Rodrigo Amaro.}

É óbvio que, pelo fato de as atividades serem feitas depois da oficina, muitos alunos se limitaram a dar como resposta informações anotadas por eles durante a minha exposição. Todavia, ainda que muitos tivessem seguido esse caminho na parte textual da atividade, na parte visual corroboravam a representação do hip hop como instrumento de guerra.

Ao perguntar aos alunos sobre o que eles entendiam por ñandereko, em forma de texto e de desenho, é que pude perceber quão intensas são as transformações relativas nas percepções desta parcela da população da reserva, que compreendem aspectos relativos à sua própria cultura e à vida dos jovens na reserva. Acredito que, neste caso, estas transformações estejam estritamente relacionadas aos efeitos da "cultura" sobre a cultura 
(CARNEIRO DA CUNHA, 2009), e também à "cultura da violência" sobre a cultura ${ }^{13}$. Isto é, os impactos da violência por sobre categorias nativas como a categoria ñandereko, como estamos abordando ao longo deste artigo.

Algumas interpretações que, de alguma maneira, fugiram do padrão, advindas de alunos convertidos ao neoprotestantismo, colocavam o cristianismo como saída para o ethos guerreiro, isto é, de outra forma, mesmo demonstrando um afastamento em relação ao hip hop, acabavam endossando a visão do hip hop como cultura da violência, quando colocavam em suas respostas o cristianismo como saída para essa assunção de um ethos guerreiro via cultura hip hop.

\section{Imagem 5 - Armas apreendidas pelos capitães durante as rondas noturnas.}

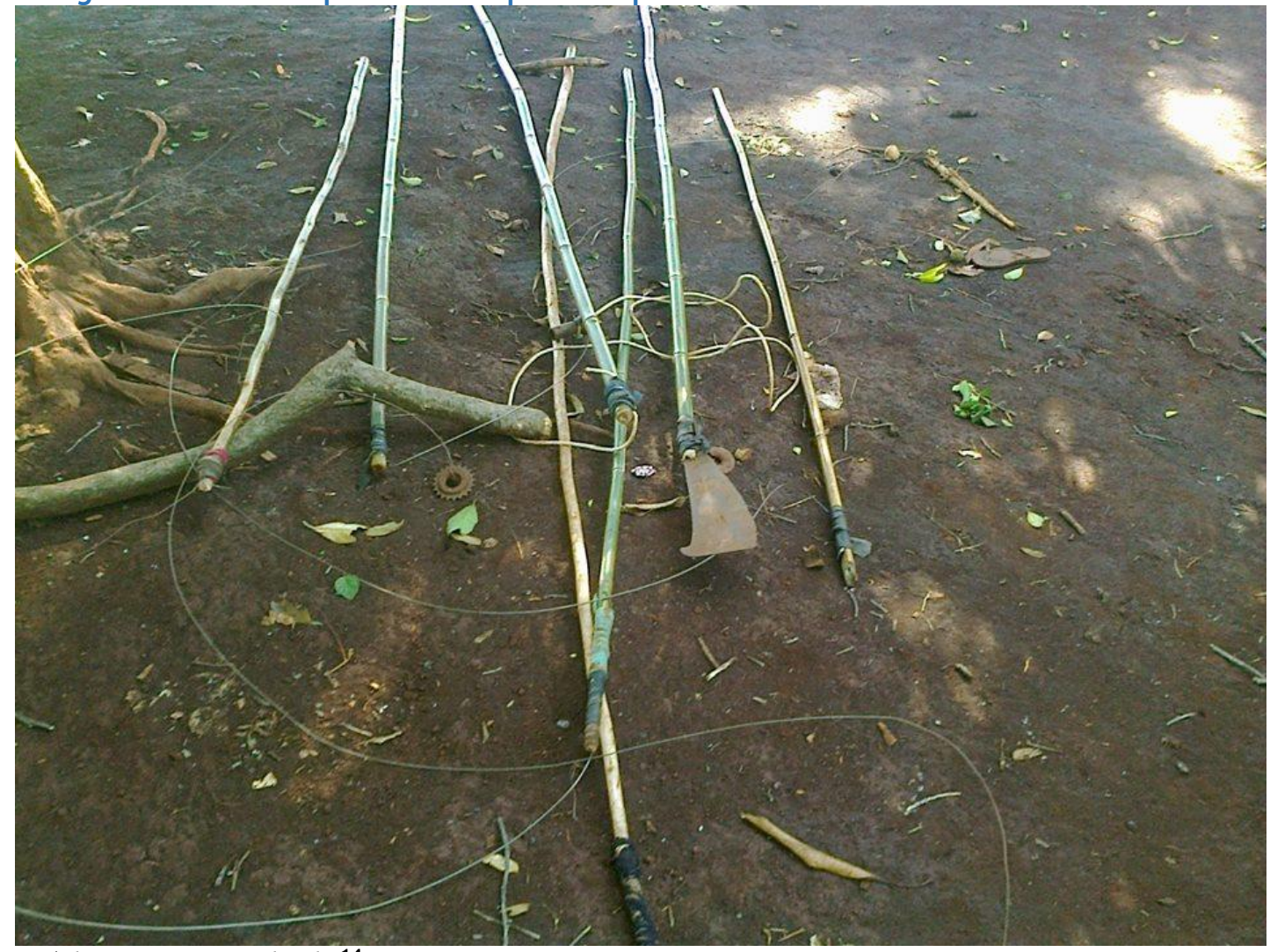

Créditos João Machado ${ }^{14}$.

Após abordar algumas representações dos alunos das escolas, nesta perspectiva de cruzar os dados, perguntei-me como os integrantes dos grupos de rap interpretavam a categoria ñandereko? Suas interpretações têm uma articulação com os dados obtidos na escola indígena? A resposta para a segunda questão é, ao mesmo tempo, positiva e negativa.

\footnotetext{
${ }^{13}$ A este respeito, talvez fosse necessária uma outra etnografia inteira para dar conta de entender o que estamos chamando de violência a partir dos próprios olhares dos Kaiowá. Sendo assim, reconheço os limites e problemas ao mobilizar esta categoria aqui.

${ }^{14}$ Imagem gentilmente cedida por João Machado, funcionário da Funai e acadêmico indígena, que nutre interesse comum pela situação do jovem da reserva e que, de forma generosa, compartilhou muitos dados comigo durante minha pesquisa de campo.
} 
Assim, por exemplo, as respostas variavam entre afirmativas que ora diziam respeito às influências do ambientalismo do vocabulário do indigenismo em seus modos de conceituação, ora as respostas iam no mesmo sentido do que os alunos da escola entendiam como ñandereko. Por exemplo, vejamos o que Charles entende a esse respeito:

Pra mim, ñandereko é a nossa vida, entendeu? É a nossa vida, é o espaço em que a gente vive. É a realidade das quebradas, da aldeia. Pra mim é isso, né (CHARLES).

E para esboçar essa linha de pensamento também com a fala de seu irmão Kelvin, temos também a seguinte resposta:

É as nossas vidas, né. [Insisto na pergunta, dizendo como assim? Não entendi] Então, é a nossa vida de hoje, né. As nossas dificuldades que a gente passa. A gente tipo assim conta né, a realidade (KELVIN).

As respostas dadas por Kelvin e Charles sobre o que entendem por ñandereko nos remetem diretamente aos desenhos destacados nas páginas anteriores, indicando uma sobreposição de sentidos das respostas das diferentes perguntas por mim elencadas no âmbito escolar. Neste caso, de uma forma recursiva, perguntar sobre o que é o ñandereko para estes jovens e perguntar o que é o hip hop para o jovem indígena acaba indicando elementos que nos remetem a um mesmo sentido. Seja lá como for, podemos perceber que ambas as falas sobre a categoria ñandereko nos direcionam a interpretá-las de acordo com vetores transformacionais.

Na Escola Agostinho, enquanto fazia campo, pude observar muito do que César já me havia descrito na ocasião em que nos conhecemos. Mas foi no contato com os alunos que pude notar o gosto de grande parte deles por símbolos que remetem à violência de forma bastante expressiva. Os jovens da reserva, com máquinas improvisadas, tatuavam uns aos outros com técnicas bastante rudimentares, conhecidas popularmente como "tatuagens de cadeia", em alusão às tatuagens feitas de forma improvisada dentro dos presídios.

Para ilustrar um pouco dessa estética, observei, por exemplo, um jovem que tinha na parte frontal dos dedos de uma de suas mãos as seguintes letras em sequência $V, I, D, A$, $L, O, K, A$, e na outra, as letras $D, E, U, S$, formando, paradoxalmente, a "inconstante" equação "Vida Loka"15 e "Deus". Clemerson, do Bro MCs, por seu turno, em uma de suas pernas, tinha uma caveira com uma faca atravessada de cima abaixo em chamas. Todas as tatuagens são feitas com tintas de caneta que, com o tempo, ficam com os traços esverdeados. Mas já ao findar o meu campo de pesquisa, este jovem recorreu a um jovem tatuador Kaiowá de outra

\footnotetext{
${ }^{15}$ A expressão Vida Louca ou Vida Loka é a tradução mais comumente encontrada no Brasil do estilo de vida denominado como Thug Life, criado pelo rapper norte-americano Thupac Shakur. Em resumo, diz respeito a um código de conduta que devia ser respeitado pelos moradores dos bairros periféricos das cidades da costa Oeste dos Estados Unidos, visando à cooperação e ao respeito. No Brasil, esse modus operandi ficou conhecido por conta das músicas dos Racionais MC's. Todavia, por aqui, a expressão é lida de outra maneira, sendo muitas vezes erroneamente vista como apologia ao crime e ao uso de drogas.
} 
aldeia para cobrir sua tatuagem com grafismos indígenas que muito se assemelhavam a motivos Kayapó.

Рara me ajudar a pensar sobre essa conjugação simbólica, estabeleço aqui um diálogo com os escritos de Janice Caiafa sobre o movimento punk do Rio de Janeiro dos anos 80. A autora nos mostra como estes jovens compunham o seu visual com imagens que, aos olhos de qualquer cidadão comum, são altamente contraditórias.

\begin{abstract}
"A suástica evidente na camisa e a negação de que seu uso naquele momento se ligam ao discurso que ela representaria, acoplam-se num caligrama provisório para um funcionamento que trabalha esse espaço entre o mostrar e o dizer - ostentar um símbolo/sustentar uma doutrina. Caligrama que se arma a cada pergunta minha para entender esse exercício, quando aparecem os comentários de força de negação variável ("é claro que não", e um mais raro "usamos para chocar") e se conectam com a evidência do símbolo. O que está em jogo é a própria representação. (...) Os punks dão fuga à representação por certo uso da figura e da palavra" (CAIAFA, 1985, p. 82).
\end{abstract}

Nas escolas em que fiz campo, sobretudo na Escola Agostinho, as imagens das tatuagens dos alunos não eram diferentes. Além da expressão "Vida Loka", citada antes, que expressa uma série de significados, observei também que os alunos tinham predileção também pela imagem de uma marca de vestuário que ficou bastante conhecida nos anos 90, a grife Bad Boy. Esta marca tem como símbolo principal dois olhos cerrados mostrando fúria e violência. Essa tatuagem, juntamente com a tatuagem das armas, das cruzes e das caveiras, foi a imagem que mais pude observar marcando os corpos dos jovens na reserva, e também nos cadernos e nos suportes das escolas.

Neste sentido, percebia nos jovens uma vontade expressa por buscar essa estética do embate e do amedrontamento, seja nas suas roupas, nos seus cadernos e até mesmo, como vimos, em seus corpos. Assim, percebemos um ponto de ligação entre esses dados obtidos nas escolas e o universo vivido e representado pelos jovens do Bro MCs e dos Jovens Conscientes. Mas como já destacamos, esses mesmos símbolos, em diversos corpos, conjugavam-se com versículos e frases cristãs, tais como "Deus é fiel", "O Senhor é meu pastor", "Jesus", entre outros.

Acredito que esse dado de pesquisa seja interessante por nos possibilitar problematizar um aspecto relativo à noção de pessoa (Tupi)guarani, amplamente discutido na bibliografia, especialmente sistematizado por Viveiros de Castro em sua obra sobre os Araweté (1986). Isto é, me refiro à instabilidade da pessoa e à dualidade da alma Guarani. Neste sentido, eu me arriscaria a relacionar o comportamento agressivo dos jovens à parcialidade da alma animal e o comportamento mais contido e receptivo ao desejo pelo estado de aguyje (estado de perfeição, plenitude) ${ }^{16}$, buscado pelos Kaiowá.

Retomando as reflexões apresentadas anteriormente por Janice Caiafa (1985), como vimos os punks jogavam com as categorias e símbolos contraditórios com o intuito de

\footnotetext{
${ }^{16}$ Essas traduções são apresentadas por Valéria Macedo (2009).
} 
causar um curto-circuito naqueles que visualizam esses códigos em suas roupas e corpos. Já no caso das tatuagens inscritas nos corpos indígenas, de forma diversa, não creio que tenham por objetivo gerar tais curtos-circuitos. Pelo contrário, o próprio ato do querer ser igual diferindo e do ser diferente se igualando, por si só, já configura um curto-circuito, que só pode ser entendido se estabelecermos um exercício de comparação que extrapole os limites Guarani, pensando-os dentro do quadro Tupi. Dito de outro modo, o paradoxo dos símbolos inscritos nos corpos indígenas, me arrisco a dizer, obedece à inconstância dessas almas selvagens, nas quais a contradição, diferentemente da nossa lógica de pensamento pautada nesse ou naquele, não comporta o pensamento do e/ou em uma mesma equação, não parecendo configurar um problema. Indo mais além, a diferença fundante percebida nesses dois tipos de contradições expressos nos dois diferentes casos etnográficos é que, no caso indígena, vão muito além do querer causar um curto-circuito via representação. Na verdade, para os jovens Kaiowá, então, o que está em jogo é capturar essas diferentes potências relacionais, neste caso, me refiro às possibilidades relacionais do mundo cristão e às formas de produzir alteridade, tendo em vista os símbolos de violência expressos nas tatuagens.

\section{CONSIDERAÇÕES FINAIS}

O leitor deve ter percebido, ao longo da problematização dos dados, sobretudo aqueles obtidos pelos trabalhos escolares, que, embora pudéssemos arriscar algumas conclusões mais gerais dos (des) entendimentos do que viria a ser o hip hop, há uma heterogeneidade de comportamento entre os jovens. De todo modo, gostaria de chamar a atenção aqui para a existência de um imenso abismo entre aquele que tem envolvimento com o hip hop e está em contato estreito com a dimensão da cultura com aspas (CARNEIRO DA CUNHA, 2009), isto é, da objetivação da cultura, e o jovem que vive na reserva e gosta de rap e breake dance. Sendo assim, os jovens do Bro MCs, de modo diverso se comparado aos integrantes do Jovens Conscientes e demais jovens consumidores do rap nas aldeias, estão em uma posição intermediária dessa separação, mantendo relações com os dois pólos dessa complexa equação. Em outras palavras, os componentes do Bro MCs se relacionam tanto com um público consumidor que aprecia o rap indígena como "cultura", quanto também transitam em meio a uma dimensão que consome o rap (indígena) a nível interno e que nada tem a ver com os efeitos da escola sobre a cultura (e o hip hop).

Vimos, então, que a estética da violência, ou melhor, a estética do embate, pode ser observada de diversas formas: nas roupas, na postura corporal, nas tatuagens, nas letras e na fisionomia. Em suma, gostaria de terminar essa seção destacando os curtos-circuitos existentes na compreensão do entendimento do hip hop entre os jovens da reserva, bem 
como também chamar a atenção para a existência de uma sobreposição deste entendimento com o que compreendem pelo ñandereko atual dos jovens da reserva. Assim, uma forma possível de leitura desses mal-entendidos passa por analisar as sucessivas traduções correntes desta expressão entre os jovens da reserva indígena de Dourados.

Mas mesmo com tudo isso, me arrisco a ir além, colocando mais uma vez a questão da produção da diferença, dessa vez, no âmbito dos embates geracionais, como outro fator explicativo para essa visão do ñandereko, isto é, o que quero dizer é que ver o ñandereko do jovem como cultura da violência é o mesmo que dizer, ou ressaltar, mais uma vez, uma forma de produzir diferença interna, neste caso, entre aqueles que se intitulam portadores da tradição versus aqueles que se lançam de forma mais intensa nesse movimento de captura de forças exteriores ao sócius.

\section{REFERÊNCIAS}

BENITES, Tonico. A escola na ótica dos Ava Kaiowá: impactos e interpretações indígenas. Rio de Janeiro: Editora Contra Capa, 2013.

BRAND, Antônio. J. 0 impacto da perda da terra sobre a tradição kaiowá/guarani: os difíceis caminhos da palavra. Tese (Doutorado) - Programa de Pós-Graduação em História da Pontifícia Universidade Católica, Porto Alegre. 1997.

CAIAFA, Janice. 0 movimento punk na cidade. Rio de Janeiro, Editora Jorge Zahar, 1985.

CARNEIRO DA CUNHA, Manuela. "Cultura" e cultura: conhecimentos tradicionais e direitos intelectuais. In: Cultura com aspas. São Paulo, Cosac \& Naify, 2009. p. 313-356.

CARVALHO, Rodrigo Amaro de. Rimas de Si, Batidas de Outrem (e Vice-Versa): estratégias de visibilidade e regimes de alteridade dentre os rappers kaiowá (Reserva Indígena de Dourados/MS). Tese (Doutorado) - Programa de Pós-Graduação em Antropologia Social, Museu Nacional, Rio de Janeiro, 2018.

GALLOIS, Dominique. A escola como problema: algumas posições. In: CARNEIRO DA CUNHA, Manuela; CESARINO, Pedro N. (org.). Políticas culturais e povos indígenas. São Paulo, Cultura Acadêmica, 2014. p. 511.

LEMOS BARBOSA, Pe. A. Pequeno vocabulário Tupi-Português. Rio de Janeiro: Livraria São José, 1951. Disponível em: Biblioteca Digital Curt Nimuendajú http://www.etnolinguistica.org

MACEDO, Valéria. Nexos da diferença: cultura e afecção em uma aldeia guarani na Serra do Mar. Tese de Doutorado - Programa de Pós-Graduação em Antropologia Social (USP), São Paulo, 2009.

MAYBURY-LEWIS. A sociedade xavante. Rio de Janeiro: Francisco Alves, 1984.

MELIÀ, Bartomeu; GRÜNBERG, Georg; GRÜNBERG, Paz. Etnografia del Paraguay Contemporaneo: Los Paĩ-tavyterã. Asunción, CEPAG, 2008, $2^{\text {a }}$ edición. 
MONTARDO, Deise Lucy. Através do Mbaraka. Música, Dança e Xamanismo Guarani. Tese de Doutorado, FAFLCH, São Paulo, USP, 2002.

MONTEIRO, John Manuel. "Os Guarani e a história do Brasil Meridional". In: M. Carneiro da Cunha (ed.), História dos índios no Brasil. São Paulo: FAPESP/Cia das Letras/SMC, 1992. p. 475-498.

MONTOYA, António Ruiz de. Arte, vocabulario, tesoro e catecismo de la lengua guaraní por Antonio. Publicado nuevamente sin alteración alguna por Julio Platzmann, Leipzig, 1876.

PEREIRA, Levi Marques. Imagens Kaiowa do Sistema Social e seu Entorno. Tese de Doutorado Programa de Pós-Graduação em Antropologia Social/USP, São Paulo, 2004.

"0 pentecostalismo kaiowá: uma aproximação aos aspectos históricos e sociocosmológicos". In: WRIGTH, Robin. (Org.). Transformando os Deuses. Vol. II. $1^{\text {a }}$ Ed. Campinas: Editora Unicamp, 2004b. p. 267-302.

. "A Reserva Indígena de Dourados - RID, Mato Grosso do Sul: a atuação do Estado brasileiro e o surgimento de figurações indígenas multiétnicas". Artigo no prelo. S/D.

PIMENTEL, Spensy K. Sansões e Guaxos - Suicídio Guarani e Kaiowá, uma proposta de síntese. Dissertação (Mestrado) Programa de Pós-Graduação em Antropologia Social, Universidade de São Paulo, São Paulo, 2006.

. "Entre nhemyrõ e $v y^{\prime} a e^{\prime} y$. interpretações sobre motivos e atitudes dos suicidas guarani-kaiowa". ANPOCS, Caxambu/MG, 2007.

SCHADEN, Egon. Aspectos fundamentais da cultura guarani. São Paulo: Editora Pedagógica e Universistária EDUSP, 1974.

SILVESTRE, Célia Foster. Entretempos: Experiência de Vida entre os Kaiowa e Guarani a partir de seus Jovens. Tese de Doutorado. Araraquara: UNESP, 2011.

VIVEIROS DE CASTRO, Eduardo Batalha. Araweté. Os Deuses canibais. Rio de Janeiro, Editora Jorge Zahar, 1986.

Recebido em 31 de janeiro de 2021. Aprovado em 10 de agosto de 2021. 